\title{
O discurso parlamentar sobre a presença obrigatória da filosofia e da sociologia no ensino médio entre 1997 e 2008
}

\section{The parliamentary speech on the mandatory presence of philosophy and sociology in high school between 1997 and 2008}

\section{Gustavo Cravo de Azevedo}

Doutorando na Pontifícia Universidade Católica do Rio de Janeiro, Rio de Janeiro, Rio de Janeiro, Brasil. gustavo_cravo@hotmail.com

ORCID: https://orcid.org/0000-0003-2743-3503

Recebido em 19 de junho de 2018

Aprovado em 12 de setembro de 2018

Publicado em 23 de janeiro de 2019

RESUMO: O trabalho tem como objetivo principal contar e analisar a trajetória de institucionalização da Sociologia como disciplina obrigatória no ensino médio entre os anos 1983 e 2008, com atenção para seus avanços e retrocessos. Além do foco nos estados, o estudo acompanha as duas tramitações de projetos de lei federal. A primeira, em 2001, sem sucesso, a segunda, em 2008, com sucesso. Nas duas tentativas, são analisados os discursos produzidos pelos parlamentares nas duas Casas do Congresso, a Câmara dos Deputados e o Senado Federal. Entre os argumentos favoráveis à obrigatoriedade da disciplina, destacam-se os objetivos de boa formação da juventude brasileira e construção de uma sociedade democrática e cidadã. Entre os argumentos contrários, as dificuldades práticas dessa empreitada e a suposição de que os conteúdos de Sociologia e Filosofia já estariam contemplados em outras disciplinas de Humanidades. Palavras-chave: Filosofia; Sociologia; Ensino Médio; Projeto de Lei; Congresso Nacional.

\begin{abstract}
The main objective of this study is to analyze and analyze the trajectory of institutionalization of Sociology as a compulsory subject in secondary education between 1983 and 2008, with attention to its advances and setbacks. In addition to the focus on the states, the study follows the two steps of federal bills. The first, in 2001, without success, the second, in 2008, successfully. In both attempts, the speeches produced by the parliamentarians in the two Houses of Congress, the Chamber of Deputies and the Federal Senate are analyzed. Among the arguments favorable to the compulsory nature of the discipline, the objectives of good training of the Brazilian youth and the construction of a democratic and citizen society stand out. Among the opposing arguments, the practical difficulties of this work and the assumption that the contents of Sociology and Philosophy would already be contemplated in other disciplines of Humanities. Keywords: Philosophy. Sociology. High School. Federal Bills. Congress.
\end{abstract}




\section{Introdução}

O artigo traz reflexões contendo a reconstituição da trajetória dos dois projetos de lei - PL 3178/19971 e PL 1641/2003² que tramitaram no Congresso Nacional entre 1997 e 2008 nos quais se propôs a presença obrigatória da Sociologia e da Filosofia no ensino médio. Foi possível observar que os argumentos favoráveis e desfavoráveis à presença das duas disciplinas, embora sejam disciplinas distintas, foram apresentados de forma indissociável no Congresso Nacional.

Os discursos dos deputados e senadores que eram favoráveis à obrigatoriedade das disciplinas durante o período da tramitação dos projetos foram organizados em cinco eixos divididos da seguinte forma: (1) fortalecimento da cidadania; (2) formação crítica - no sentido da Sociologia contribuir para a análise da realidade e a Filosofia para a reflexão; (3) formação para o trabalho; (4) protagonismo dos jovens como agentes transformadores da realidade; (5) quinto e último, que apareceu em menor frequência, a justificativa da Sociologia e da Filosofia como disciplinas com conteúdo próprio, enquanto ciências, e que possuem contribuições aos jovens e ao ensino médio. Os argumentos contrários foram mobilizados no sentido de que a contratação de professores geraria ônus para os Estados; não respeitaria a autonomia das escolas; bem como seriam conteúdos que poderiam ser abordados pela História e/ou pela Geografia; e, por último, que alguns estados brasileiros não possuíam centros formadores em Ciências Sociais e em Filosofia no período.

A atuação pró-aprovação no curso da tramitação do projeto de lei dentre os sociólogos foi realizada principalmente pelos sindicatos de sociólogos, Federação Nacional dos Sociólogos do Brasil (FNSB) e pelo Sindicato dos Sociólogos do Estado de São Paulo (SINDSESP) ${ }^{3}$, que lançaram inclusive dois manifestos ${ }^{4}$ expondo as razões em que expuseram a necessidade da aprovação da matéria (CARVALHO, 2004). Essa mobilização interferiu na dinâmica de tramitação dos projetos de lei, pois naquele momento a comunidade acadêmica de sociólogos (e cientistas sociais em geral) estava bastante desmobilizada com essa questão em particular (AZEVEDO, 2014). Appel et al (2014, p. 195) afirma que houve uma luta conjunta de filósofos e sociólogos em diversos momentos e confirma que a comunidade acadêmica de Filosofia esteve pouco mobilizada. A atuação contrária foi feita principalmente pelo lobby da chamada "indústria do vestibular" e pelo Ministro da Educação da época, Paulo Renato. Os cursos pré-vestibulares não queriam contratar mais professores. O Ministério da Educação no período utilizou principalmente o argumento de que o conteúdo das disciplinas deveria ser abordado de forma interdisciplinar (MORAES, 2011).

\section{Sobre o caminho institucional de um projeto de lei}

Para propor modificações na Lei de Diretrizes e Bases da Educação Nacional (LDB) de 1996, é necessária aprovação de lei ordinária ${ }^{5}$. Como já dito no capítulo anterior, por tratar dos objetivos, das finalidades e da organização da Educação de um país, a LDB só pode ser modificada por meio de lei. 
Uma das maneiras de se iniciar o movimento pela criação de projeto de lei ordinária é que os grupos interessados na aprovação redijam o texto da proposta e busquem algum deputado federal, senador, ou partido que transforme a proposta encaminhada em projeto de lei e encaminhe para a Mesa Diretora de uma das duas Casas. Além dessa maneira, os deputados e senadores também podem, por conta própria ou de seus partidos, redigir propostas e apresentá-las como projeto de lei ${ }^{6}$.

A proposta de lei ordinária deve ser aprovada no Congresso e depois ter a sanção presidencial. O Congresso Nacional é composto pela Câmara dos Deputados e pelo Senado. É indiferente se o projeto é primeiramente apreciado e discutido na Câmara dos Deputados ou no Senado, pois, de qualquer maneira, ele terá que ser discutido em ambas as Casas.

Antes da apreciação da proposta pelo Plenário das Casas, os projetos passam pelas comissões internas de acordo com a matéria. Nas Comissões, as propostas são analisadas por grupos menores de parlamentares. É o local onde se busca aprofundar o debate das matérias antes de elas serem submetidas à análise do Plenário.

Existem várias comissões internas, tanto na Câmara dos Deputados quanto no Senado. Os projetos só passam pelas comissões responsáveis. Todos os projetos passam pela Comissão de Constituição, Justiça e de Cidadania da Câmara dos Deputados e do Senado, salvo intervenção da Mesa Diretora da Casa. A passagem por essa Comissão tem a intenção de que o projeto de lei não fira a Constituição Federal. É um controle constitucional.

Para as matérias específicas a serem analisadas, como um projeto de lei que altera a LDB/96, é necessário que o projeto passe pela Comissão específica em cada uma das Casas, a Comissão de Educação (CE) no Senado e a Comissão de Educação, Cultura e Desporto (CECD) na Câmara dos Deputados.

As Comissões dão seu parecer sobre o projeto de lei, que são terminativos ou conclusivos $^{7}$. Dessa maneira, não é aberta discussão em Plenário sobre o projeto.

O Regimento da Câmara dos Deputados, no artigo 24, II, estabelece quando o projeto será conclusivo nas Comissões ou se deverá também ser apreciado pelo Plenário. As Comissões devem discutir e votar projetos de lei dispensando a competência do Plenário em geral sobre as matérias, exceto nos casos: de lei complementar; de código; de iniciativa popular; de Comissão; oriundos do Senado; que tenham recebido pareceres divergentes; em regime de urgência; cuja matéria não possa ser objeto de delegação. Ou seja, em projetos de lei ordinária, a grande maioria dos projetos em tramitação, as Comissões têm poder conclusivo, o que é um grande poder.

Se passar pelos Plenários das duas Casas, caso não haja dispensa dessa necessidade pelas comissões, o projeto é submetido à Presidência da República que pode: sancionar, vetar parcialmente ou vetar totalmente.

Caso o projeto seja sancionado, imediatamente ele se transforma em lei, o que aconteceu em 2008, quando o projeto de lei 1.641/2003 se transformou na lei $n^{\circ} 11.684 / 2008$. 


\section{Discurso dos parlamentares sobre a obrigatoriedade da presença da filosofia e da sociologia no ensino médio}

O primeiro projeto a propor a obrigatoriedade das disciplinas no ensino médio foi o PL 3178/1997 que tramitou entre 1997 e 2001 no Congresso Nacional. Foi finalizado com o veto do presidente Fernando Henrique Cardoso. O segundo projeto, o PL 1641/2003, tramitou entre 2003 e 2008 e teve êxito, resultando na lei federal $n^{\circ}$ 11.684/2008.

Em 11 anos desde o início da primeira proposta, centenas de discursos foram produzidos pelos parlamentares, os não-especialistas em ensino de Sociologia ou ensino de Filosofia. Este artigo irá citar apenas destacar alguns deles. Como já dito na introdução do trabalho, todos os discursos favoráveis podem ser compreendidos dentro de cinco eixos divididos da seguinte forma: (1) fortalecimento da cidadania; (2) formação crítica - no sentido da Sociologia contribuir para a análise da realidade e a Filosofia para a reflexão; (3) formação para o trabalho; (4) protagonismo dos jovens como agentes transformadores da realidade; (5) quinto e último, que apareceu em menor frequência, a justificativa da Sociologia e da Filosofia como disciplinas com conteúdo próprio, enquanto ciências, e que possuem contribuições aos jovens e ao ensino médio.

\section{Projeto de lei 3.178/1997}

O PL 3178/1997 foi apresentado pelo deputado Padre Roque Zimmerman (PT/ PR). Logo, sua tramitação começou pela Câmara dos Deputados. Foi enviado à Comissão de Educação e depois à Comissão de Constituição, Justiça e de Cidadania.

Na Comissão de Educação, Cultura e Desporto (CECD), o relator do projeto foi o deputado João Thomé Mestrinho (PMDB/AM). Em sua justificativa para a aprovação, prevaleceu a argumentação calcada na Lei de Diretrizes e Bases da Educação Nacional (LDB/96), na qual ele cita artigos que comprovam a vocação da LDB para a cidadania, o aprimoramento do educando como pessoa humana, em respeito ao bem comum e à ordem democrática. Além disso, cita a ditadura militar como diretamente responsável pelas duas disciplinas estarem há tanto tempo longe do currículo. Afinal, a ditadura militar, privilegiou disciplinas moralizadoras no currículo ao invés de disciplinas que pudessem ensejar pensamento crítico sobre o regime, diz ele.

O projeto chega à Comissão de Constituição, Justiça e de Cidadania (CCJC) e como relator é designado o deputado Waldir Pires (PT/BA). O deputado afirma que não há obstáculo de natureza constitucional e jurídica à tramitação livre do projeto. Além dessa análise, objetivo da CCJC, o deputado faz elogios ao projeto de lei, o que ele não é obrigado a fazer nessa Comissão. Afirma que é muito importante a aprovação do projeto para melhor inserção dos jovens na sociedade, no questionamento às injustiças sociais e para que os jovens "compreendam a importância do conflito das ideias e dos fatos sociais, dentro dos quais, naturalmente, hão de viver".

O projeto passou pelas duas Comissões com parecer terminativo, ou seja, sem necessidade de ir à Plenário. O PL 3178/97 chega ao Senado e, com isso, ganha uma nova nomenclatura e abreviatura: Projeto de Lei Originária da Câmara (PLC) n 009/2000.

O PLC 09/00 chega à Comissão de Educação e é distribuído ao senador Álvaro Dias (PSDB/ $\mathrm{PR}$ ), filósofo, que dá parecer favorável e sugere que a matéria vá para a pauta na Comissão 
de Educação. O parecer do senador se apoia no artigo 35 da LDB/96, artigo que explicita que o ensino médio é a última etapa da educação básica e cita suas finalidades como primeira justificativa para a presença da Sociologia e da Filosofia. Ele espera que, dessa maneira, o ensino médio assegure "aos alunos a compreensão da relação existente entre o saber, historicamente construído e criticamente apreendido, e o processo produtivo, entre o conhecimento e a produção". Outro argumento é que os conhecimentos das disciplinas "são fundamentais para a construção da cidadania e da democracia, na medida em que constituem chaves para a compreensão do desenvolvimento das sociedades...". Interessante comentar que o parecer favorável quanto ao mérito dessa Comissão não impede que o projeto tenha que ir a Plenário, em turno único ${ }^{8}$. Na Câmara dos Deputados, o projeto foi aprovado com parecer conclusivo das comissões, o que significa a dispensa da discussão do projeto pelo Plenário da Casa.

Houve três sessões no Plenário do Senado Federal para discutir o projeto que prevê a presença obrigatória das disciplinas Sociologia e Filosofia no ensino médio. As sessões ocorreram nos dias 13/06/2001, 29/08/2001 e 19/09/2001. Abaixo é apresentado um compêndio com os principais momentos da discussão.

No dia 13/06/2001, a discussão começa com o Presidente do Senado no período, senador Jader Barbalho (PMDB/PA), passando a palavra ao líder do governo, senador Romero Jucá (PSDB/RR). O senador faz encaminhamento contrário à aprovação da lei, motivado por comunicação do Ministério da Educação, na pessoa do próprio Ministro Paulo Renato. O discurso se constrói afirmando que as duas disciplinas podem ter seus conteúdos abordados por outras disciplinas, de acordo com a Lei de Diretrizes e Bases da Educação Nacional (LDB/96). Ele cita três argumentos para justificar: (1) que a LDB fala em temas e não em disciplinas; (2) que interferir dessa maneira vai contra a autonomia pedagógica de cada escola; (3) que não há quantidade suficiente de professores, o que irá gerar problema principalmente para as escolas do interior. Concluindo, ele pede que os senadores ali presentes dos partidos da base do governo - PFL, PSDB, PPB, PTB e PMDB - votem contrariamente ao projeto.

Em seguida, todos os senadores que pedem a palavra, inclusive da base parlamentar do governo, com exceção do senador Bello Parga (PFL/MA), defendem a aprovação da matéria contra o discurso do líder do governo. Pediram a palavra os senadores Lúcio Alcântara (PSDB/CE), Marina Silva (PT/AC), Heloísa Helena (PT/AL), Roberto Saturnino (PSB/RJ), Emilia Fernandes (PT/RS), Casildo Maldaner (PMDB/SC), Ademir Andrade (PSB/ PA), Bello Parga (PFL/MA), Pedro Simon (PMDB/RS) e Roberto Requião (PMDB/PR). O senador Bello Parga (PFL/MA) afirma que o espírito da LDB é dar autonomia para as escolas, e que elas escolham quais disciplinas irão incluir no currículo. O senador Lúcio Alcântara (PSDB/CE) diz que não está convencido de que os conteúdos de Filosofia sejam trabalhados na escola e que a sociedade anseia por essas discussões. Cita o livro O Mundo de Sofia, de Jostein Gaarder, segundo ele um livro muito vendido no Brasil e no mundo, como exemplo dessa demanda da sociedade. Defende que a Filosofia não tem nada de vã, e que ela é muito importante para a vida de todos.

A senadora Marina Silva (PT/AC) diz não entender o posicionamento do Ministério da Educação e aborda que, já para a época, é um engano apostar todas as fichas em uma formação 
mais "técnica" em detrimento de uma formação mais "humana". Defende que o modelo fordista de repetição técnica cada vez tem menos espaço e o que mais importa é a capacidade do aluno de conseguir se adaptar aos novos desafios da vida profissional. Para isso, o maior capital que pode ser dado aos alunos é o capital de administrar a informação. Levanta mais um argumento dizendo que "o que levava 50 anos para ocorrer, hoje num período de menos de dez anos...". Por último, diz que não acredita em neutralidade axiológica do conhecimento, e que é importante permitir que o jovem construa seu ponto de vista como sujeito de transformação.

O senador Roberto Requião (PMDB/PR) destaca que os governos públicos não querem as disciplinas por não ter professores disponíveis e que o ensino particular não quer mais duas disciplinas por razões econômicas.

Romero Jucá (PSDB/RR) tenta uma manobra para que a proposta saia de pauta volte à Comissão de Educação, para que seja discutida na presença do Ministro da Educação. $A$ manobra não funciona e é marcada nova sessão para a discussão.

$\mathrm{Na} 2^{\text {a }}$ Sessão sobre a discussão, ocorrida no dia 29/08/2001, quem preside o Plenário é o senador Edson Lobão (PMDB/MA).

O senador Romero Jucá (PSDB/RR), líder do governo no Plenário do Senado, pede a fala e inicia comentando que abriu um requerimento para que o projeto seja analisado somente no dia 18 de setembro. Apesar do tempo entre 13/06/2001 e 29/08/2001 ser destinado para que o governo pensasse melhor sobre o projeto, o senador alega que no dia 11 de setembro de 2001, o Ministro da Educação Paulo Renato estará presente na reunião da Comissão de Educação do Senado, ocasião na qual discursará sobre o PLC 09/00. Ele pede a compreensão dos demais senadores e promete que no dia 18 de setembro não tentará nenhuma manobra propondo emenda, atrasando a discussão ou fazendo com que o projeto volte à Câmara dos Deputados, e também não pedirá novamente o adiamento da discussão.

A senadora Heloísa Helena (PT/AL) pede a palavra e critica o governo FHC, entre outras coisas, pela política de privatizações e pela ingerência também em dificultar a aprovação desse projeto. Comenta que, em votação, o projeto será aprovado. Ela admite o poder que os senadores da base governista possuem de adiar a votação, ainda que a oposição não queira. E faz o alerta de que, no fundo, há o medo de que o Presidente Fernando Henrique Cardoso, um sociólogo, tenha que vetar o projeto. Sua fala é aplaudida por uma plateia lotada.

$O$ encaminhamento da votação torna-se também um momento de continuidade da discussão, pois senadores do PT e do PMDB desafiam o líder do governo e afirmam que se o projeto for posto em votação, será aprovado.

O senador José Alencar (PMDB/MG), com a palavra, comunica aos colegas senadores sobre as entidades que assinaram o Manifesto em defesa da Sociologia e da Filosofia no Ensino Médio, pela aprovação do Projeto de Lei da Câmara dos Deputados $n^{\circ} 9 / 2000$. Chama a atenção para o fato de que o documento é assinado por autoridades como o Presidente da Conferência Nacional dos Bispos do Brasil, Dom Jayme Henrique Chemello, e o Presidente do Conselho Nacional de Igrejas Cristãs do Brasil. Ele esclarece que fala como líder do PMDB, que é contrário ao adiamento da votação, dada a importância do projeto, mas que o voto é aberto para a bancada do partido. 
O forte apoio católico, com a assinatura do presidente da CNBB e de reitores de diversas universidades católicas se deu possivelmente em apoio ao deputado Padre Roque Zimmerman (PT/PR). Roque Zimmerman é formado em Filosofia/Teologia e se identifica como Padre, inclusive sua atuação religiosa consta como sua identidade na Câmara dos Deputados. Além disso, possivelmente houve interesse cristão na aprovação da Filosofia no ensino médio.

O Manifesto em defesa da Sociologia e da Filosofia no Ensino Médio, pela aprovação do Projeto de Lei da Câmara dos Deputados $n^{\circ}$ 9/2000, citado pelo senador José Alencar (PMDB/ MG) levanta quatro argumentos principais na defesa da presença das duas disciplinas no ensino médio. O primeiro argumento afirma que a Filosofia é uma ciência de 2500 anos e que a Sociologia sempre fez parte do currículo desde a República, com um breve intervalo entre 1964 e 1982, e que vários estados, após 1982, já oferecem a disciplina (ROMANO, 2009). Esse argumento da Sociologia não condiz totalmente com a verdade já que a Sociologia entrou de maneira mais forte no currículo em 1925 com a Reforma Rocha Vaz e deixou o ensino médio com a Reforma Capanema de 1942. Antes de 1925, ela esteve presente, mas não de maneira universal e, além disso, é necessário problematizar que o sentido moralizante da Sociologia no ensino médio em 1925 é bem diferente do sentido democrático de seu retorno a partir de 1982.

O segundo argumento interpreta a LDB/96 compreendendo que ela prevê a presença das disciplinas já que o educando deverá demonstrar "domínio dos conhecimentos de filosofia e de sociologia necessários para o exercício da cidadania” (LDB, 1996). O terceiro e o quarto argumentos dizem respeito à formação proposta aos jovens pelo ensino médio brasileiro. Defende que uma formação humanística, em que os jovens tenham capacidade de análise, é fundamental e, ainda, que o ensino médio seja de qualidade, progressista, científico e humanista. Cerca de 350 entidades representativas da sociedade civil foram consultadas e se manifestaram em apoio ao presente Manifesto.

O senador Álvaro Dias (PSDB/PR) cita trecho do argumento do Professor Franklin Leopoldo e Silva, filósofo e professor da USP, presente no relatório que teve parecer favorável na Comissão de Educação do Senado:

\footnotetext{
"Existe um lado pelo qual a Filosofia ocupa, na estrutura curricular - isso vale também para a Sociologia —, uma posição análoga a qualquer outra disciplina. Há o que aprender, há o que memorizar, há técnicas a serem dominadas, há, sobretudo, uma terminologia específica a ser devidamente assimilada." (Projeto de lei 3178/1997 de autoria do deputado Padre Roque Zimmermman, p. 2)
}

O realce pelo senador de trecho do projeto de lei é importante porque envolve nessa sessão legislativa a primeira defesa das disciplinas como competência específica, e não como instrumento para a cidadania ou para a crítica. Interessante comentar que o discurso político é alheio à defesa de competências específicas das disciplinas e sua bagagem científica. É um discurso que se constrói pelo clamar dos senadores pela necessidade de instrumentos para que o jovem possua uma formação crítica, em termos gerais. Ou seja, é um discurso que não envolve a opinião dos especialistas em Sociologia e em Filosofia. O projeto novamente não é votado e nova data é marcada. 
Em 19 de setembro de 2001, o líder do governo, senador Romero Jucá (PSDB/ $\mathrm{RR}$ ) é o primeiro a pedir a palavra e enumera quatro argumentos contrários à aprovação do projeto. Ele afirma que: (1) estados e cidades menos desenvolvidos terão problemas para preencher essas vagas de professores; (2) a LDB/96 é um projeto que não prevê o ensino organizado por disciplinas e sim temas que devem ser tratados de maneira interdisciplinar; (3) não existem cursos de formação de Sociologia e/ou de Filosofia nos estados do Acre, Amapá, Mato Grosso, Rondônia, Roraima e Tocantins; (4) não há formandos suficientes para ocupar essas vagas nacionalmente. Dessa forma, encaminha a proposta de que o projeto volte à Comissão de Educação do Senado e lá seja reestruturado no sentido de que, caso aprovado, a lei não tenha aplicabilidade imediata, que a obrigatoriedade das duas disciplinas seja lançada daqui a "quatro, cinco, seis anos".

Todos os outros onze senadores que pediram a palavra durante a sessão a usaram em defesa da aprovação do projeto: os senadores Paulo Hartung (PPS/ES), Tião Viana (PT/C), Marina Silva (PT/AC), Roberto Saturnino (PSB/RJ), Emilia Fernandes (PT/ RS), Álvaro Dias (PSDB/PR), Ademir Andrade (PSB/PA), Casildo Maldaner (PMDB/ SC), Arlindo Porto (PTB/MG), Lúcio Alcântara (PSDB/CE), Maguito Vilela (PMDB/GO).

Os argumentos dos senadores foram muito parecidos aos apresentados nas duas sessões anteriores. A linha de raciocínio sustentou que as duas disciplinas são importantes para construir o aluno cidadão que saiba interpretar a realidade e interferir nela, que seja um "agente ativo da sua História", nas palavras do senador Paulo Hartung (PPS/ES).

O projeto de lei foi encaminhado à votação e teve o seguinte resultado. Dos 65 senadores que votaram, 40 votaram SIM, 20 votaram NÃO, e cinco se abstiveram de votar.

O bloco aliado ao governo era composto pelos partidos PFL, PSDB, PPB, PTB e ao PMDB. No dia da votação, contava com 51 dos 65 senadores presentes. Ou seja, muitos senadores não seguiram a recomendação do governo para votar.

No dia 09/01/2001, em despacho do Presidente da República, Fernando Henrique Cardoso, ao Presidente do Senado, Senador Romero Jucá (PSDB-RR), é dado o veto ao projeto de lei. O texto argumenta que a inclusão das duas disciplinas trará ônus para os Estados e que não há número suficiente de profissionais formados.

\section{Projeto de lei $1.641 / 2003$}

Em 2003, há nova iniciativa de garantir a presença obrigatória das duas disciplinas via projeto de lei. O projeto de lei anterior, o PL 3.178/97, proposto pelo deputado Padre Roque Zimmermman (PT/PR), enfrentou oposição do Ministro da Educação Paulo Renato e do líder do governo no Senado, senador Romero Jucá (PSDB/RR). A tramitação do PL $1.641 / 2003$ passa por alguns percalços, mas tem trajetória relativamente tranquila na Câmara dos Deputados e no Senado. Foram poucos momentos de oposição e de apresentação de argumentos contrários ao projeto. Ele não teve passagem pelo Plenário da Câmara dos Deputados e contou com passagem rápida e sem maiores problemas pelo Plenário do Senado.

Há diferenças entre o PL 1.641/2003 proposto pelo deputado Ribamar Alves (PSB/MA) e o PL 3.178/1997, proposto pelo deputado Padre Roque Zimmermman (PT/ 
PR). O PL 1.641/2003 incorpora quase na totalidade o texto do PL 3.178/1997 e traz algumas novidades. O projeto de 1997 somente cita o ensino de Sociologia como composto por características e objetivos mutatis mutandis ao ensino de Filosofia. A argumentação do projeto de lei de 2003, excluído o trecho de alteração da legislação da LDB, sequer cita a palavra Sociologia. A construção do texto do projeto de lei é todo e somente feito em cima de argumentação da importância da Filosofia no ensino médio.

O projeto passa sem problemas pela Câmara dos Deputados e pelo Senado. Isso se explica pelo Presidente da República eleito para os períodos 2003-2006 e 2007-2010 ser Luís Inácio Lula da Silva (PT), pelo fato do Ministro da Educação de boa parte desse período, Fernando Haddad, ser claramente a favor da aprovação, e também pela mudança da composição partidária na Câmara dos Deputados e no Senado. A demora na tramitação, cinco anos entre 2003 e 2008, se deu mais pelas turbulências que sofreu o governo Lula9 .

O projeto de lei 1.641/2003 passa tranquilamente pela Câmara dos Deputados e chega ao Senado somente em 2008 ganhando a nomenclatura Projeto de Lei da Câmara (PLC) n. 4/2008.

Na aprovação do parecer na Comissão de Educação, o senador Valter Pereira (PMDB/MS) justifica que a Filosofia e a Sociologia já estão evidenciadas em documentos produzidos pelo Conselho Nacional de Educação/Câmara de Educação Básica (CNE/CEB) e cita o documento de 1998, Diretrizes Curriculares Nacionais para o Ensino Médio (DCNEM), que estabelece que os fundamentos do ensino médio se assentam sob os conceitos da estética, política e ética, conceitos propícios das duas disciplinas e conceitos indissociáveis da etapa do ensino médio.

Três dias depois, o projeto ganha a condição de requerimento de urgência assinado por grupo de dezenove senadores e segue para o Plenário do Senado.

Na sessão no Plenário do dia 10/05/2008, a senadora Ideli Salvatti (PT/SC) solicita uma inversão de pauta a favor do projeto que prevê a obrigatoriedade da Sociologia no ensino médio. É atendida e é também a única que pede a palavra para opinar sobre o projeto. A senadora Ideli defende três argumentos. Primeiro, ela afirma que a ditadura militar retirou as disciplinas do currículo e as substitui por Educação Moral e Cívica. Em seguida, a defesa se dá pelo argumento de que as disciplinas, no ensino médio, colaboram para a formação de uma visão humanista nas novas gerações para que se formem conceitos, caráter, moral. O terceiro argumento é que o projeto já tramita há onze anos no Congresso Nacional e já foi bem discutido tanto que chegou até a etapa da sanção presidencial da outra vez.

O projeto é aprovado e, logo depois, sancionado pelo presidente em exercício, o VicePresidente da República José Alencar. Com isso, dá-se a aprovação da lei no 11.684/2008 de 2 de junho de 2008.

\section{Considerações finais}

No artigo foram levantados diversos discursos sobre a Sociologia e a Filosofia no ensino médio a partir do clamor dos deputados pela necessidade de instrumentos para formar o jovem com características do bom cidadão e do jovem crítico. Essa defesa é feita a partir de discursos alheios às construções dos especialistas, vozes que não aparecem nesse momento 
da defesa do projeto. A Sociologia e a Filosofia puderam ser observadas como instrumentos compensatórios da formação no ensino médio, momento em que é citada a falta genérica de uma formação humanística, um dos termos mais utilizados pelos deputados e senadores.

É interessante ressaltar aqui que os comentários dos deputados e senadores sobre o projeto, sejam comentários favoráveis ou desfavoráveis, raramente separam os argumentos sobre a Sociologia e a Filosofia. Na prática, a defesa ou o ataque ao projeto é feito com os mesmos argumentos. E os projetos de lei, que visaram incluir duas disciplinas diferentes entre si no ensino médio, cada uma com espaço próprio, correram como se fosse uma discussão única.

O atual momento é importante para o debate porque há incertezas sobre a consolidação da presença da Sociologia e da Filosofia no ensino médio. A lei 13.415/2017, conhecida como lei da reforma do ensino médio revogou a lei $n^{0} 11.684 / 2008$, lei que garante a presença obrigatória das duas disciplinas no ensino médio. Importante deixar o registro de que a aprovação da lei, recentemente revogada, ocorreu após a tramitação de dois projetos de lei pelo Congresso Nacional por onze anos. Amplo e rico debate foi realizado para a aprovação.

\section{Referências}

AZEVEDO, Gustavo Cravo de. Sociologia no Ensino Médio: uma trajetória políticoinstitucional (1982-2008). 222 folhas. Dissertação de mestrado - Programa de PósGraduação em Ciência Política, Universidade Federal Fluminense, 2014. Disponível em: http://www.labes. fe.ufrj.br/download/?ch=eb30fe564525c94a6b61ebb72a0e9cf2. Acesso em 19/06/2018.

BRASIL. Congresso Nacional. Câmara dos Deputados. Padre Roque Zimmemann. Projeto de Lei 3178/1997. Altera dispositivos do art. 36. Da Lei n 9.394, de 20 de dezembro de 1996, que estabelece as diretrizes e bases da educação nacional - Brasília, DF, 1997.

BRASIL. Congresso Nacional. Câmara dos Deputados. Ribamar Alves. Projeto de Lei 1641/2003. Altera dispositivos do art. 36. Da Lei n 9.394, de 20 de dezembro de 1996, que estabelece as diretrizes e bases da educação nacional - Brasília, DF, 2003.

BRASIL. Lei $n^{\circ} 11.684,2$ de junho de 2008. Altera o art. 36 da Lei $n$ 9.394, de 20 de dezembro de 1996, que estabelece as diretrizes e bases da educação nacional, para incluir a Filosofia e a Sociologia como disciplinas obrigatórias nos currículos do ensino médio.

BRASIL. Lei $\mathbf{n}^{\circ}$ 13.415, de 16 de fevereiro de 2017. Conversão da Medida Provisória $n^{\circ} 746$. Altera substancialmente o Ensino Médio.

BRASIL. Ministério da Educação. Lei 9394/1996. Lei de Diretrizes e Bases da Educação Nacional. Brasília, 1996.

CARVALHO. Lejeune Mato Grosso de. (Org.). Sociologia e ensino em debate: experiências e discussão de sociologia no ensino médio. ljuí, Rio Grande do Sul. Ed. Unijuí, 2004.

LANGON, Maurício; AGRATTI, Laura, APPEL, Emmanuel; GALLO, Silvio; HEUSER; Ester 
Maria Dreher. Uma conversa-viagem: Entre o passado e o futuro do ensino de filosofia. Revista Sul-Americana de Filosofia e Educação. Número 21: nov/2013-abr/2014, p. 193-219. Disponível em: http://periodicos.unb.br/ojs32/index.php/resafe/article/view/4644. Acesso em 19/06/2018.

MORAES, Amaury. Ensino de Sociologia: Periodização e Campanha pela Obrigatoriedade. Cad. Cedes, Campinas, vol. 31, n. 85, p. 359-382, set.-dez. 2011. Disponível em: http://www. scielo.br/pdf/ccedes/v31n85/04v31n85. Acesso em 19/06/2018.

MORAES, Amaury. Por que Sociologia e Filosofia no Ensino Médio? In: Sociologia e ensino em debate: experiências e discussões de sociologia no ensino médio. ljuí, Rio Grande do Sul. Ed. Unijuí, 2004.

ROMANO, Fábio Geraldo. A luta em defesa da Sociologia no ensino médio (1996-2007): um estudo sobre a invenção das tradições. Dissertação de mestrado apresentada no Programa de Pós-Graduação em Educação Escolar da Faculdade de Ciências e Letras, UNESP/ Araraquara. 2009.

ZANARDI, Gabriel Seretti. A re-introdução da Sociologia nas escolas públicas: caminhos e ciladas para o trabalho docente. Dissertação de mestrado apresentada no Programa de Pós-Graduação em Educação Escolar da Faculdade de Ciências e Letras, UNESP/ Araraquara. 2009.

\section{Notas}

1 Disponível em: http://www.camara.gov.br/proposicoesWeb/fichadetramitacao?idProposicao=19225. Acesso em 19/06/2018.

2 Disponível em: http://www.camara.gov.br/proposicoesWeb/fichadetramitacao?idProposicao=127294. Acesso em 19/06/2018.

${ }^{3}$ Boletins sindicais do Sindicato dos Sociólogos do Estado de São Paulo (SINDSESP) defenderam a inclusão da Sociologia no ensino médio no sentido de garantir milhares de vagas para professores de Sociologia via concurso público. Há pouca bibliografia sobre a atuação dos sindicatos de sociólogos estaduais na luta nacional pela inclusão das disciplinas, por isso, foram citadas apenas a entidade nacional e a entidade estadual de São Paulo. Desconheço como foi a atuação dos filósofos.

${ }^{4}$ O primeiro manifesto, de 2001, foi intitulado como Manifesto em defesa da Sociologia e Filosofia no ensino médio e pela aprovação do PLC 9/00. O segundo manifesto, de 2006, foi chamado de Manifesto Apoiamos Sociologia e Filosofia no ensino médio para ampliarmos a cidadania no Brasil. Ambos tiveram apoios de diversas entidades dentre movimentos sociais, associações de classe, associações acadêmicas, associações estudantis e etc.

${ }^{5}$ Existem dois diferentes tipos de leis: leis complementares e leis ordinárias. As leis complementares têm esse nome porque são leis complementares à Constituição Federal (CF) de 1988. Ou seja, elas existem para regulamentar assuntos específicos conforme previsto no texto constitucional. Já as leis ordinárias são leis que regulamentam ordinariamente os assuntos de relevância do cotidiano nacional. São aquelas que a CF/88 não determinou expressamente que fossem regulamentados por leis complementares.

${ }^{6}$ Outras maneiras, ainda, são: (1) que o Poder Executivo apresente ao Congresso proposta de lei; (2) ou que haja um projeto de lei de iniciativa popular. 
${ }^{7}$ Há uma diferença de nomenclatura entre as duas Casas no parecer que aprova o projeto de lei sem necessidade de passar pelo Plenário, embora seja possível que deputados e senadores apresentem recurso contra o projeto. Na Câmara dos Deputados, esse instrumento é chamado parecer conclusivo. Já no Senado, o mesmo instrumento é chamado parecer terminativo.

8 É necessário que qualquer projeto passe pela Comissão que avalie sua constitucionalidade apenas uma vez. Como já passou por essa Comissão na Câmara dos Deputados, não será necessário passar novamente no Senado.

${ }^{9}$ As acusações sobre o mensalão, por exemplo, ilustram essas pressões.

\section{Correspondência}

Gustavo Cravo de Azevedo - Av. Pedro Calmon, 550, Cidade Universitária da Universidade Federal do Rio de Janeiro, Reitoria Pró-Reitoria de Pessoal, CEP: 21.941-901, Rio de Janeiro, Rio de Janeiro, Brasil.

\section{(9)(1)(9)}

This work is licensed under a Creative Commons Attribution-NonCommercial 4.0 International (CC BY-NC 4.0) 